1 Digestibility of Calanus finmarchicus wax esters in Atlantic salmon

2 (Salmo salar) freshwater presmolts and seawater postsmolts

3 maintained at constant water temperature

4

5

6 A. OXLEY ${ }^{1}$, A.S. BOGEVIK ${ }^{1,2}$, R.J. HENDERSON ${ }^{3}$, R. WAAGB ${ }^{4}$, D.R. $7 \quad$ TOCHER $^{3} \&$ R.E. OLSEN ${ }^{1}$

8

9

${ }^{1}$ Institute of Marine Research (IMR), Matre Aquaculture Research Station, Matredal,

Norway; ${ }^{2}$ Department of Biology University of Bergen, Bergen, Norway. ${ }^{3}$ Institute of Aquaculture, University of Stirling, Scotland, UK; ${ }^{4}$ National Institute of Nutrition and Seafood Research (NIFES), Bergen, Norway.

Correspondence: A. Oxley, Institute of Marine Research, P.O. Box 1870 Nordnes, 5817

Bergen, Norway; Email: anthony.oxley@imr.no; Tel: +47-55906502; Fax: +47-55238531.

Running Title: Wax ester digestion in Atlantic salmon

Keywords: Bile, digestion, fatty acids, growth, intestine, long-chain fatty alcohols, salinity, smoltification, triacylglycerol. 
Calanoid copepods are a rich source of n-3 highly unsaturated fatty acids (HUFA) for potential use in aquafeeds. However, as copepod oil is primarily composed of wax esters (WE), there are concerns over the efficiency of wax ester, versus triacylglycerol (TAG), digestion and utilisation in fish. As smoltification represents a period of major physiological adaptation, the present study examined the digestibility of a high wax ester diet (Calanus oil; $230 \mathrm{~g} \mathrm{~kg}^{-1}$ diet; 48\% WE, 26\% TAG), compared to a triacylglycerol diet (fish oil; $230 \mathrm{~g} \mathrm{~kg}^{-1}$ diet; 58\% TAG), in Atlantic salmon freshwater pre-smolts and seawater post-smolts, of similar age (9 months) and weight (112 $\mathrm{g}$ and $141 \mathrm{~g}$ initial respectively), over a 98 day period at constant temperature and lighting regimes. Fish grew significantly better, and possessed lower feed conversion ratios (FCR), in seawater than freshwater. However, total lipid apparent digestibility coefficient (ADC) values were significantly lower in seawater fish, as were total fasted bile volumes. Dietary Calanus oil also had a significant effect, reducing growth and lipid ADC values in both freshwater and seawater groups. Post-smolts fed dietary Calanus oil had the poorest lipid ADC values and analysis of faecal lipid class composition revealed that $33 \%$ of remaining lipid was wax ester and $32 \%$ fatty alcohols. Dietary prevalent 22:1n-11 and 20:1n-9 fatty alcohols were particularly poorly utilised. A decrease in major bile acid, taurocholate, concentration was observed in the bile of dietary Calanus oil groups which could be related to the lower cholesterol content of the diet. It is suggested that, following smoltification and rapid growth in seawater, there is a lag phase in digestive function where bile production is not sufficient to emulsify and render wax esters available for hydrolytic action by luminal lipases. These effects appear to be related to the life stage of the fish and could also represent an upper limit of wax ester inclusion in diets. 
Calanoid copepods are potential candidates as a novel feed resource for the aquaculture industry to alleviate the dependency on marine fish oils as a source of n-3 highly unsaturated fatty acids (HUFA) (Olsen et al. 2004). Calanus finmarchicus is the most abundant zooplankton species in North European coastal waters and can comprise $>60 \%$ of dry weight as lipid contained in an oil sac that occupies most of the body cavity (Bauermeister \& Sargent 1979). However, Calanus species synthesize and store lipid primarily as wax esters, although small reserves of triacylglycerol are also present (Sargent \& Falk-Petersen 1988). Wax esters differ from triacylglycerol as a dietary neutral lipid source in that fatty acids are esterified to a long-chain fatty alcohol rather than glycerol and, consequently, are more hydrophobic in aqueous systems, i.e. the environment of the intestinal lumen (Bauermeister \& Sargent 1979).

It is generally accepted that although carnivorous fish species (e.g. those with pyloric caecae) can utilise dietary wax esters well, digestion and absorption of triacylglycerol is more efficient (Olsen \& Ringø 1997). In a variety of fish species, Patton et al. (1975) observed that wax ester utilisation was approximately 4 times slower than triacylglycerol being attributed to higher hydrophobicity and associated lower biliary emulsification in the intestine. Furthermore, hydrolytic activity of bile salt-dependent lipase (BSDL) is known to be 1 to 2 orders of magnitude lower towards wax esters than triacylglycerol (Tocher \& Sargent 1984). Due to these compounding factors, there are concerns into the inclusion of wax ester-rich diets in aquaculture.

Nevertheless, when rainbow trout (Oncorhynchus mykiss) were fed marine zooplankton, $<5 \%$ of ingested lipid was excreted in faeces with the long-chain monoenic $22: 1 n-11$ fatty alcohol accumulating in the wax ester and free fatty alcohol fractions (Sargent et al. 1979). However, it is recognised that Atlantic salmon are more sensitive to dietary manipulation with digestibility of macronutrients typically higher in rainbow trout (Krogdahl et al. 2004). 
74 Moreover, a recent study in 250-500 g Atlantic salmon found a significant reduction in lipid

75

76

77

78

79

80

81

82 digestibility when fed a high wax ester diet (Bogevik et al. In press). This is in contrast to a study in larger salmon (>1 kg) where no differences were found (Olsen et al. 2004). Thus, there maybe a size/age-related effect on intestinal adaptation to dietary wax esters in Atlantic salmon.

The difference in dietary neutral lipid between the freshwater environment, where triacylglycerol predominates, and the marine environment, where wax esters are more commonplace (Henderson \& Tocher 1987), places an adaptive physiological demand on the intestine, and associated organs, where bile and lipolytic capacities are increased (Patton \& Benson 1975; Tocher \& Sargent 1984). As smoltification represents a period of considerable physiological adaptation in Atlantic salmon, where significant changes in ionoregulation and lipid metabolism occur (Folmar \& Dickhoff 1980; Sheridan 1989), the present study was undertaken to elucidate the utilisation of dietary wax esters in freshwater pre-smolts and seawater post-smolts. As the physico-chemical behaviour of lipids in the intestinal lumen is affected by temperature (Hofmann 1976), both groups of fish were kept at constant temperature throughout the feeding period with freshwater fish maintained on a short-day, and seawater fish on a long-day, lighting regime. 
Fish, diets and experimental design

One hundred and twenty Atlantic salmon (Salmo salar L., Mowi strain; Norwegian breeding programme) 9 month-old pre-smolts of $113 \mathrm{~g}$ average weight were anaesthetised in $0.4 \%$ $(\mathrm{w} / \mathrm{v})$ benzocaine and measured for weight and length before being individually tagged with a passive induced transponder (Trovan pit tag, ID100, Stavanger, Norway). Subsequently, fish were distributed equally between six $1.5 \times 1.5 \times 1.0 \mathrm{~m}$ fibreglass tanks and supplied with aerated freshwater maintained at $9.8^{\circ} \mathrm{C}\left( \pm 1.1^{\circ} \mathrm{C}\right)$ throughout the entire experimental period. Similarly, 120 Atlantic salmon 9 month-old post-smolts of $141 \mathrm{~g}$ average weight were tagged and distributed between 6 tanks supplied with aerated seawater maintained at $8.8^{\circ} \mathrm{C}( \pm$ $\left.0.1^{\circ} \mathrm{C}\right)$. Freshwater pre-smolt $(\mathrm{FW})$ and seawater post-smolt $(\mathrm{SW})$ groups were kept under respective short-day and long-day lighting regimes according to the photoperiod model of Bjornsson et al. (2000).

Two diets were fed to both freshwater and seawater groups, in triplicate tanks, which differed only in dietary oil source: either containing 30\% fish oil (control diet; FO) or 30\% oil extracted from the marine copepod Calanus finmarchicus (experimental diet; CO). Diets were prepared at the Norwegian Institute of Fisheries and Aquaculture (Bergen, Norway) as outlined in detail previously (Olsen et al. 2004) and contained $0.01 \%$ yttrium oxide as a marker of digestibility. Fish were fed respective diets to excess twice a day for a period of 98 days.

After the experimental period had elapsed, fish were anaesthetised in $0.4 \%$ benzocaine for measurement of weight and length. Faeces were also stripped from fish according to Ringø (1991), pooled per tank, and stored at $-80^{\circ} \mathrm{C}$. Remaining fish were starved for $72 \mathrm{~h}$ prior to sampling the gall bladder where bile volume was recorded, using a $5 \mathrm{~mL}$ syringe with $0.1 \mathrm{~mL}$ resolution, and the bile stored at $-80^{\circ} \mathrm{C}$. 
Analysis of diets and faeces

Diets and faeces were heated at $105^{\circ} \mathrm{C}$ for $24 \mathrm{~h}$ to obtain dry weight, followed by analysis of yttrium oxide according to Ottera et al. (2003). Yttrium was determined in feed and faeces by use of an ICP-MS (inductive-coupled plasma - mass spectrometry) method after wet digestion in a microwave oven (Ottera et al. 2003).

Total lipid of diets and faeces was extracted with chloroform/methanol $(2: 1, \mathrm{v} / \mathrm{v})$ according to Folch et al. (1957). Dilute $\mathrm{HCl}$ (3 M, 30\% of original faecal weight) was added prior to the last extraction. The chloroform hypophase was evaporated to dryness in vacuo at room temperature before resuspending the lipid residue in circa $1 \mathrm{~mL}$ of chloroform/methanol $(2: 1, \mathrm{v} / \mathrm{v})$ containing $0.05 \%(\mathrm{w} / \mathrm{v})$ BHT. Extracted lipid was stored under $\mathrm{N}_{2}$ at $-80^{\circ} \mathrm{C}$ for further analysis.

Lipid class composition of total lipid was determined by double-development highperformance thin-layer chromatography (HPTLC) coupled with scanning densitometry, as described by Olsen \& Henderson (1989). HPTLC plates (Merck, Darmstadt, Germany) were initially developed to halfway in methyl acetate/isopropanol/chloroform/methanol/0.25\% aqueous $\mathrm{KCl}(25: 25: 25: 10: 9, \mathrm{v} / \mathrm{v})$ before developing fully with hexane/diethyl ether/acetic acid $(85: 15: 1, \mathrm{v} / \mathrm{v})$. Lipid classes were visualised by spraying the plate with $3 \%(\mathrm{w} / \mathrm{v})$ copper acetate in $8 \%(\mathrm{v} / \mathrm{v})$ phosphoric acid and charring at $160^{\circ} \mathrm{C}$ for $15 \mathrm{~min}$. Lipid classes were quantified using a CAMAG TLC Scanner 3 and WinCATS software (CAMAG, Muttenz, Switzerland). Identities of individual lipid classes were confirmed by running authentic standards alongside samples on HPTLC plates which also compensated for inter-plate variation when quantifying each lipid class within a linear area utilising established standard equations.

To determine fatty acid and long-chain fatty alcohol composition of diets and faeces, 
extracted lipid was subjected to acid-catalysed transesterification using $1 \%(\mathrm{v} / \mathrm{v}) \mathrm{H}_{2} \mathrm{SO}_{4}$ in methanol (Palmquist \& Jenkins 2003) with 17:0 fatty acid and fatty alcohol added as internal standards. Resultant fatty acid methyl esters (FAME) were extracted and purified by TLC on $20 \times 20 \mathrm{~cm}$ plates as described previously (Tocher \& Harvie 1988). Long-chain fatty alcohols present in extracted lipid from the Calanus oil diet and faeces of fish fed dietary Calanus oil were identified on TLC plates as a single component and recovered from silica by elution with chloroform/methanol $(2: 1, \mathrm{v} / \mathrm{v})$ before conversion to acetate derivatives by reaction with acetic anhydride/pyridine (1:2, v/v) (Farquhar 1962). Prior to GC analysis, fatty alcohol acetates were purified on TLC plates as described for FAME.

Fatty acid methyl esters and fatty alcohol acetates were separated and quantified by gas liquid chromatography using a $30 \mathrm{~m} \times 0.32 \mathrm{~mm}$ i.d. fused silica capillary column coated with ZB-Wax (Phenomenex, Macclesfield, UK) and a Thermo Finnigan Trace gas chromatograph. Hydrogen was used as carrier gas and temperature programming was from 50 to $150^{\circ} \mathrm{C}$ at a rate of $40^{\circ} \mathrm{C} \min ^{-1}$, from 150 to $180^{\circ} \mathrm{C}$ at $1.5^{\circ} \mathrm{C} \min ^{-1}$, from $180^{\circ} \mathrm{C}$ to $192^{\circ} \mathrm{C}$ at a rate of $0.5^{\circ} \mathrm{C}$ $\min ^{-1}$ and then to a final temperature of $220^{\circ} \mathrm{C}$ at $40^{\circ} \mathrm{C} \mathrm{min}^{-1}$. Individual components were identified by comparison with known standards. The absolute amounts of individual fatty acids and long-chain alcohols present were calculated by reference to the internal standard (Olsen et al. 2004).

\section{Bile analysis}

Analysis of conjugated bile salts was performed essentially according to Coca et al. (1994). To $100 \mu \mathrm{L}$ of bile, $5 \mu \mathrm{L}$ of internal standard (dexamethasone, $20 \mathrm{mg} \mathrm{mL}^{-1}$ ) was added before diluting 50-fold with $0.7 \mathrm{M}$ phosphate buffer ( $\mathrm{pH} 7.0$ ). Bile salts were purified by reversedphase affinity chromatography using Sep-Pak $\mathrm{C}_{18}$ cartridges (Waters, MA, USA) preconditioned with $5 \mathrm{~mL}$ methanol, $10 \mathrm{~mL}$ water, and $5 \mathrm{~mL} 0.7 \mathrm{M}$ phosphate buffer $(\mathrm{pH}$ 
173 7.0). Cartridges were subsequently washed with $10 \mathrm{~mL}$ water, $3 \mathrm{~mL}$ of $10 \%(\mathrm{v} / \mathrm{v})$ acetone, and $10 \mathrm{~mL}$ water before eluting bile salts with $5 \mathrm{~mL}$ of methanol. The eluant was dried under a stream of nitrogen, redissolved in mobile phase and filtered through a $0.2 \mu \mathrm{m}$ syringe filter (Nalgene, Nalge Nunc International, Rochester, USA). Conjugated bile salts were separated using a Waters Alliance HPLC system with 2690 Separation Module and a LiChrospher RP18 column $(4.6 \times 250 \mathrm{~mm}$, id $5 \mu \mathrm{m})($ Supelco, Inc., Bellefonte, USA) with methanol/0.5 $\mathrm{M}$ acetate buffer $\mathrm{pH} 4.3(70: 30, \mathrm{v} / \mathrm{v})$ as mobile phase. Detection was via a Waters 996 Photodiode Array Detector set at $\lambda=205 \mathrm{~nm}$ with reference to authentic standards. Bile osmolality was measured using a Fiske one-ten osmometer (Fiske Associates, MA, USA) with calibration and reference solutions $\left(290 \mathrm{mOsm} \mathrm{L}^{-1}\right)$ from the manufacturer.

\section{Calculations and statistical treatment}

Specific growth rate (SGR), apparent digestibility coefficient (ADC), condition factor $(k)$, and feed conversion ratio (FCR) were calculated using the equations given in Olsen et al. (2004). Thermal growth coefficient (TGC) was calculated according to Iwama \& Tautz (1981). Fatty acid and long-chain alcohol digestibilities were calculated based on the concentration of individual components in total lipid $\left(\mu \mathrm{g} \mathrm{mg}^{-1}\right)$. Data are given as \pm S.D. for replicate tanks where $n=3$. All statistical analysis was performed using SPSS software for Windows (SPSS, Michigan, USA). Data were checked for homogeneity of variances by the Levene test and, where necessary, transformed via arcsin (percentage data) or Ln functions. Effects of dietary or salinity treatments were assessed by multivariate analysis using standard general linear model (GLM) methods. Differences in fatty acid and long-chain fatty alcohol digestibilities were analysed via one-way ANOVA followed by Tukey's post hoc test. Significance was accepted at a level of $P<0.05$ in all cases. 


\section{Growth and feeding}

200

During the 98 day feeding period, seawater post-smolts (SW) grew significantly better than

201

202

203

204

205

206

207

208

209

210

211

212

213

214

215

216

217

218

219

220

221

222 freshwater pre-smolts (FW) with fish fed the control fish oil (FO) diet attaining a significantly higher weight gain than those fed the Calanus oil (CO) diets. Pre-smolts fed the FO and CO diets grew from circa $112 \mathrm{~g}$ to $266 \mathrm{~g}$ and $241 \mathrm{~g}$ respectively while post-smolts increased from circa $141 \mathrm{~g}$ to $381 \mathrm{~g}$ and $356 \mathrm{~g}$ respectively (Fig. 1a). This resulted in daily specific growth rates (SGR) of 0.86 and 0.77 for pre-smolts and 1.00 and 0.95 for post-smolts fed the respective FO and $\mathrm{CO}$ diets (Fig. 1d). However, taking into account the slight difference in water temperature between the freshwater and seawater tanks, the thermal growth coefficient (TGC) became more pronounced between pre- and post-smolt groups with values of $1.65(\mathrm{FO})$ and $1.44(\mathrm{CO})$ for pre-smolts and $2.35(\mathrm{FO})$ and 2.19 (CO) for postsmolts (Fig. 1e).

Similar trends in fish length development were observed as for weight development with post-smolts attaining significantly longer lengths than pre-smolts with fish maintained on the FO diet being significantly longer than those on the $\mathrm{CO}$ diet (Fig. 1b). However, the difference in length between the pre- and post-smolt groups was less pronounced than the difference observed between these groups for weight development. This resulted in increased condition factor $(k)$ values for post-smolts over 98 days (1.13 at day 0 to $1.31 / 1.32$ for $\mathrm{FO} / \mathrm{CO}$ at day 98) while $k$ values for pre-smolts remained relatively constant (1.23 at day 0 to 1.24/1.21 for FO/CO at day 98) (Fig. 1c). Thus, post-smolts possessed significantly lower $k$ values than pre-smolts at day 0 yet significantly higher $k$ values at day 98 .

Feed conversion ratios (FCR) were significantly higher for pre-smolts, with values of 0.77 (FO) and $0.74(\mathrm{CO})$, than post-smolts: $0.64(\mathrm{FO})$ and $0.67(\mathrm{CO})$ (Fig. 1f). FCR values were higher for fish fed dietary $\mathrm{CO}$ than dietary FO in freshwater and seawater groups although 
these differences were not significant.

\section{Dietary lipid composition}

Diets were identical in formulation except for the FO or $\mathrm{CO}$ supplementation at a level of 230 $\mathrm{g} \mathrm{kg}^{-1}$ feed (Table 1) or 27\% lipid by dry weight of feed (Table 2). The major difference in lipid class composition between diets was in the neutral lipid fraction with the FO diet containing predominantly triacylglycerol (TAG; 58\%) and the $\mathrm{CO}$ diet including wax esters (WE; 48\%) and TAG (26\%) (Table 2). Other major components included free (nonesterified) fatty acids (FFA) at respective levels of $17 \%$ (FO) and 13\% (CO), and also cholesterol at 11\% (FO) and 7\% (CO). Both diets contained similar amounts of individual phospholipids with phosphatidylcholine (PC) > phosphatidylethanolamine (PE) > phosphatidylinositol (PI) > phosphatidylserine (PS). Lysophosphatidylcholine (LPC), sphingomyelin (SM) and unidentified polar lipids (UPL) were individually minimal at $\leq 1 \%$. No trace of free long-chain fatty alcohols (FFAlc) in the CO diet was detected.

Absolute levels of fatty acids (FA) were $890 \mu \mathrm{g} \mathrm{mg}^{-1}$ lipid for the FO diet and $525 \mu \mathrm{g} \mathrm{mg}^{-1}$ lipid for the CO diet which additionally contained $256 \mu \mathrm{g} \mathrm{mg}{ }^{-1}$ lipid of long-chain fatty alcohols (FAlc) (Table 3). The fatty acid composition of the FO diet was predominantly monounsaturates (MUFA; 51\%) with n-3 PUFA $(23 \%) \approx$ saturates (SFA; 22\%) $>$ n-6 PUFA (3\%). 22:1n-11, 18:1n-9 and 20:1n-9 accounted for the bulk of monoenoic fatty acids, 16:0 for saturates, 22:6n-3 and 20:5n-3 for n-3 PUFA, and 18:2n-6 for n-6 PUFA. Comparatively, the CO diet contained lower levels of MUFA (35\%) in the fatty acid moiety yet higher levels of n-3 PUFA (30\%), SFA (30\%) and n-6 PUFA (5\%). Although levels of 22:6n-3 were much lower in the CO diet, the higher n-3 PUFA total was attributed to increases in 18:4n-3, 20:5n3 and 18:3n-3. Higher total SFA was due to increased 14:0. Regarding the FAlc fraction of Calanus dietary lipid, monoenes predominated at a level of $81 \%$ consisting mainly of $22: 1 \mathrm{n}$ - 
$24811(41 \%)$ and 20:1n-9 (29\%). Total polyunsaturates were particularly low in the FAlc moiety at $6 \%$ while saturates were present at a level of $13 \%$.

\section{Faecal lipid composition}

252

253

254

255

256

257

258

259

260

261

262

263

264

265

266

267

268

269

270

271

272

Lipid constituted $5 \%$ and $12 \%$ of faecal dry matter in pre-smolts fed respective $\mathrm{FO}$ and $\mathrm{CO}$ diets with post-smolts having values of $7 \%(\mathrm{FO})$ and $15 \%(\mathrm{CO})$ compared to a lipid level of $27 \%$ in both diets (Table 2). The faecal lipid of fish fed dietary FO consisted mainly of FFA $>$ cholesterol $>$ sterol esters whereas the faecal lipid of fish fed dietary CO predominated in FFAlc, WE and FFA. Compared to dietary content, relatively little TAG remained in faecal lipid with pre-smolts having the lowest levels at $4 \%$ (FO) and $0.5 \%(\mathrm{CO})$ compared to postsmolts with levels of $6 \%(\mathrm{FO})$ and $0.9 \%(\mathrm{CO})$. However, the FFA fraction was lower in the freshwater fish $(47 \%, \mathrm{FO} ; 21 \%, \mathrm{CO})$ compared to the seawater fish $(64 \%, \mathrm{FO} ; 25 \%, \mathrm{CO})$. In fish fed dietary $\mathrm{CO}$, the wax ester content of faecal lipid was highest in post-smolts $(33 \%)$ with a FFAlc fraction of 32\%. Values for pre-smolts were $25 \% \mathrm{WE}$ and $38 \%$ FFAlc. Cholesterol accounted for $23 \%(\mathrm{FW})$ and $14 \%(\mathrm{SW})$ of faecal lipid in fish fed dietary FO while values for fish fed dietary $\mathrm{CO}$ were $8 \%(\mathrm{FW})$ and $6 \%(\mathrm{SW})$. In dietary FO groups, the proportion of sterol esters increased in faecal lipid (7\%) compared to dietary lipid (4\%).

Regarding the fatty acid composition of faecal lipid, there were notable increases in the proportion of SFA in all groups of fish when compared to dietary fatty acid composition (Table 3). Saturated fatty acids levels were highest in fish fed dietary CO (59\%, FW; 52\%, SW) compared to fish fed dietary FO $(44 \%, \mathrm{FW} ; 43 \%$, SW) although the CO diet contained a higher proportion of SFA. The increases in SFA was mainly attributable to increased 16:0 and 18:0 in the FO groups while faecal lipid from the CO groups had approximately double the levels of 14:0 and 16:0 compared to dietary fatty acid composition. The total MUFA content of faecal lipid was similar in both FO and CO groups with respect to dietary lipid, 
where an increase in longer chain MUFA, such as 22:1n-11, was associated with a concomitant decrease in shorter chain MUFA such as 18:1n-9 and 16:1n-7. Proportions of PUFA in faecal lipid decreased substantially in all groups compared to dietary lipid with 22:6n-3 the predominant PUFA remaining. Levels of faecal n-3 PUFA in freshwater groups were similar at 7\%. In comparison, n-3 PUFA in seawater groups were higher in $\mathrm{CO}$ fish (11\%) than FO fish (5\%). With respect to FAlc composition, the monoenes increased from $81 \%$ in dietary Calanus lipid to $94 \%$ (FW) and $92 \%$ (SW) in faecal lipid due to an accumulation of 22:1n-11. Saturated FAlc decreased from $13 \%$ in dietary lipid to $3 \%$ and $5 \%$ in pre- and post-smolt faecal lipid respectively.

\section{Digestibility of fatty acids and fatty alcohols}

Apparent digestibility coefficient (ADC) values for total lipid were 97\% (FO) and 93\% (CO) for pre-smolts with values of $93 \%$ (FO) and $84 \%$ (CO) for post-smolts (Table 4). Total fatty acid digestibility was significantly higher in freshwater groups $(93 \%, \mathrm{FO} ; 88 \%, \mathrm{CO})$ compared to seawater groups $(79 \%$, FO \& CO) with the ADC of PUFA $>$ MUFA $>$ SFA. Decreases in fatty acid digestibility in post-smolts were due to inferior utilisation of total SFA $>$ MUFA while PUFA utilisation remained relatively unaffected at ADC values of greater than $90 \%$. However, significant decreases in the digestibility of $22: 6 n-3$ were observed in the $\mathrm{CO}$ groups with post-smolts particularly affected having an ADC for 22:6n-3 of 58\%. Of the MUFA, decreases in dietary prevalent 22:1n-11 and 20:1n-9 reflected decreased total MUFA digestibility.

Similarly, total FAlc digestibility was significantly higher in freshwater pre-smolts (78\%) than seawater post-smolts (61\%). Monoenic FAlc were particularly poorly utilised with 22:1n-11 and 20:1n-9 having the lowest values. FAlc digestibility in pre-smolts was $75 \%$ for monoenes compared to $91 \%$ and $94 \%$ for polyunsaturates and saturates respectively, while 
post-smolt values were $56 \%$ for monoenes, $84 \%$ for saturates and $80 \%$ for polyunsaturates.

299

300

Bile volume and composition

301

There were significant effects of salinity and diet on fasted bile volume with values of 2.6

302

(FO) and $2.9(\mathrm{CO}) \mathrm{mL} \mathrm{kg}^{-1}$ for pre-smolts and $1.8(\mathrm{FO})$ and $2.1(\mathrm{CO}) \mathrm{mL} \mathrm{kg}^{-1}$ for post-smolts

303

(Fig. 2a). Thus, bile volumes were higher in freshwater fish and in fish fed CO compared to

304 dietary FO. Irrespective of dietary and salinity treatments, the main bile salt was taurocholate

305

(TC) which accounted for more than $90 \%$ of the identified bile salts, with the remainder 306 being mainly taurochenodeoxycholate (TCDC). Bile composition varied with dietary treatment regarding the primary bile acid TC with the FO groups having concentrations of 447 (FW) and 434 (SW) mM compared to 422 (FW) and 427 (SW) mM for CO groups (Fig.

2c). Regarding the minor bile acid TCDC, it was the post-smolt groups that had the highest values (26 mM, FO; $21 \mathrm{mM}, \mathrm{CO})$ compared to pre-smolt groups (14 mM, FO; $8 \mathrm{mM}, \mathrm{CO})$ with FO groups having higher values than CO groups within salinity treatments (Fig. 2d). 


\section{Discussion}

324 The most apparent result of the study was that fish grew significantly better in seawater than freshwater over the 98 day feeding period. This is a typical response in post-smolts (Wedemeyer et al. 1980) following a period of up to 30 days where appetite and growth are actually suppressed after seawater transfer (Usher et al. 1991; Bendiksen et al. 2003). Furthermore, a decrease in condition factor is characteristic of fish that have undergone smoltification (Wedemeyer et al. 1980; Boeuf 1993) which was manifested at day 0 in the present study. However, condition factors of post-smolts surpassed those of pre-smolts after 98 days of feeding. Feed conversion (FCR) data confirms that seawater fish utilised diets more efficiently for growth despite increased faecal lipid content and lower lipid and dry matter apparent digestibilities (ADC). Similarly, (Krogdahl et al. 2004) found that the thermal growth coefficient (TGR) was 50\% higher in Atlantic salmon held in seawater, compared to those in freshwater, along with lower FCR and ADC values for dry matter and protein. This was concomitant with an increase in retention of digestible protein and energy in seawater fish. Thus, post-smolts utilise dietary energy mainly for increased growth, 
et al. (1991) demonstrated that freshwater-adapted Atlantic salmon smolts favour lipid deposition while seawater smolts favour protein deposition 3 months post-transfer. However, this was suggested to be an over-wintering strategy in freshwater fish as they had previously smoltified.

Although fish growth rates were higher in seawater, total lipid digestibilities decreased with salinity and dietary Calanus oil. These findings are validated by a recent study, in 250$500 \mathrm{~g}$ Atlantic salmon post-smolts, where fish maintained on dietary Calanus oil had significantly lower specific growth rates and lipid digestibilities (Bogevik et al. In press). However, no significant difference in growth was found in larger salmon (circa $1.5 \mathrm{~kg}$ ) fed dietary Calanus oil (Olsen et al. 2004) although the dietary wax ester content was lower ( $37 \%$ vs $48 \%$ in the present study). The high dietary content of wax esters in the present study could reflect an upper boundary for wax ester inclusion in diets which is supported by the findings of Bogevik et al. (In press), an effect which could be exacerbated in smaller fish post-smoltification. Therefore, the dietary wax ester: triacylglycerol ratio could be a limiting smolts appears to be a reduced capacity to hydrolyse wax esters with higher total digestibility of fatty acids due to the efficient hydrolysis of triacylglycerol present in the diet. The most 
previously, wax esters are intrinsically more hydrophobic than triacylglycerol and consequently require more amphipathic compounds, such as bile salts, cholesterol and phospholipids, to form an emulsion and render the lipid available for lipases. Although bile volume significantly increased in fish fed dietary wax esters, bile volume was still appreciably lower in the seawater group. Thus, following smoltification, it appears that smolts utilised dietary energy for growth while digestive functions, such as bile production, lagged behind. Consequently, the seawater fish were unable to adapt to the high wax ester content of the diet within the 98 day feeding period. However, a recent study, in slightly larger post-smolts, demonstrated that fish are capable of increasing bile volume in response to a high wax ester diet although not to a level where lipid ADC is not significantly affected (Bogevik et al. In press).

In addition to lower bile volumes in post-smolts, there was a significant decrease in concentrations of the primary bile salt, taurocholate, in dietary Calanus groups. As bile acids are synthesized from cholesterol in the liver, the lower dietary content of cholesterol (circa $50 \%$ ) in Calanus oil may have affected bile acid synthesis and subsequent concentrations in bile. Futhermore, it is known that hepatic cholesterol is depleted during smoltification (Boeuf, 1993). In mammals, diets containing high levels of cholesterol stimulate biliary secretion of bile acids to maintain cholesterol homoeostasis (Tuchweber et al. 1996). Conversely, in fish, it is unclear whether de novo cholesterol synthesis can compensate for decreased dietary cholesterol in bile acid formation. It is reported that a gallbladder concentration of bile salts in excess of $600 \mathrm{mM}$, and an intestinal lumen concentration approaching $50 \mathrm{mM}$, is required for efficient assimilation of wax esters in animals (Place 1992). Reported total bile salt concentrations in salmonid bile are $<500 \mathrm{mM}$ with luminal concentrations $<20 \mathrm{mM}$ when fed dietary wax esters (Tocher and Sargent 1984; Bogevik et al. In press). Although salmonids are capable of increasing bile volume and luminal wax ester 
hydrolase activity in response to dietary wax esters (Tocher and Sargent 1984; Bogevik et al. In press), it was shown that luminal lipolytic activity is lower in $300 \mathrm{~g}$ salmon compared to $1500 \mathrm{~g}$ fish (Bogevik et al. 2008).

Dietary prevalent monoenic long-chain fatty alcohols, such as 22:1n-11 and 20:1n-9, were particularly poorly utilised which reflected decreases in total fatty alcohol digestibility in dietary Calanus groups. Saturated fatty alcohol digestibilities were always superior to fatty acid analogues. In a previous study in Atlantic salmon fed dietary Calanus oil, 22:1n-11 accumulated in both wax ester and free fatty alcohol fractions of faecal lipid indicating that hydrolysis and absorption is limiting for this long-chain monoene (Olsen et al. 2004). As 22:1n-11 and 20:1n-9 alcohols are esterified primarily to 14:0 fatty acid (Sargent \& Henderson 1986), the concomitantly poor ADC value for 14:0 fatty acid in seawater fish points towards inferior hydrolysis. However, in cod (Gadus morhua) no such specificity was observed in hydrolytic activity towards fatty alcohols (Lie \& Lambertsen 1985). Although ADC values for PUFA were mostly $>93 \%$ irrespective of dietary or salinity treatment, there was a significant decrease in 22:6n-3 in fish fed dietary Calanus oil which decreased further in seawater fish to $58 \%$. The effect of salinity on the reduction of $22: 6 n-3$ ADC has been shown previously in Arctic charr (Salvelinus alpinus) even though these fish were not fed wax esters (Ringø 1991).

With regard to fish fed dietary fish oil, only a small proportion of triacylglycerol remained in faecal lipid, compared to dietary content, while the free fatty acid fraction increased significantly - especially in post-smolts. Thus, triacylglycerol hydrolysis was very efficient in both groups of fish yet the absorption of fatty acids was hindered in post-smolts. This could be due to increased concentrations of divalent cations present in the intestinal lumen of seawater fish which form complexes with long-chain fatty acids resulting in insoluble soaps (Olsen \& Ringø 1997). Indeed, significantly reduced lipid digestibility values, particularly for 
saturated and monoenic fatty acids, were obtained when Arctic charr were reared in seawater compared to freshwater (Ringø 1991). Furthermore, high concentrations of saturates and monoenes were found in the soap fraction of cod faeces (Olsen \& Ringø 1997). This agrees with data in the present study where saturated $>$ monoenic fatty acid digestibility values were 427 significantly lower in seawater faeces while digestibility of PUFA remained relatively unaffected.

Findings from this work highlight that even though the growth of salmon following smoltification and seawater acclimation remains good and superior to freshwater pre-smolts, there appears to be a lag phase in digestive functional development and adaptation to dietary wax esters at the expense of weight gain. Even fish maintained on control fish oil diets experienced significant decreases in digestibility of saturated and monoenic fatty acids. Although the digestibility of total lipid in pre-smolts fed dietary Calanus oil was significantly reduced compared to the control diet, the effect was exacerbated in post-smolts - even after 98 days. This appears to be a consequence of reduced bile volume at the expense of increased growth in post-smolts whereby a reduced quantity of bile salts cannot effectively compensate for increased hydrophobicity of wax esters present in the intestinal lumen during digestion. This effect could be due to the high wax ester content of the experimental diet and/or life stage of the fish. 
449 The project was supported by the Norwegian Research Council (no. 165051 and 172641).

450 The formulation of the diets was carried out by Harald Mundheim at the Norwegian Institute

451 of Fisheries and Aquaculture Research (Fyllingsdalen, Norway). We are indebted to Tom

452 Hansen (IMR, Matre, Norway) for advice on the preparation of the manuscript and to staff at

453 NIFES (Bergen, Norway) and IMR (Matre, Norway) for excellent technical assistance.

454

455

456

457

458

459

460

461

462

463

464

465

466

467

468

469

470

471

472 


\section{References}

474 Bauermeister, A. \& Sargent, J.R. (1979) Wax esters - major metabolites in the marine environment. Trends in Biochemical Sciences, 4, 209-211.

476

Bendiksen, E.A., Arnesen, A.M. \& Jobling, M. (2003) Effects of dietary fatty acid profile and fat content on smolting and seawater performance in Atlantic salmon (Salmo salar L.). Aquaculture, 225, 149-163.

Bjornsson, B.T., Hemre, G.I., Bjornevik, M. \& Hansen, T. (2000) Photoperiod regulation of plasma growth hormone levels during induced smoltification of underyearling Atlantic salmon. General and Comparative Endocrinology, 119, 17-25.

Boeuf, G. (1993) Salmonid smolting: a pre-adaptation to the oceanic environment. In: Fish Ecophysiology (Rankin, J.C. \& Jensen, F.B. eds.), pp. 105-135. Chapman \& Hall, London.

Boeuf, G. \& Payan, P. (2001) How should salinity influence fish growth? Comparative Biochemistry and Physiology, 130C, 411-423.

Bogevik, A.S., Tocher, D.R., Waagbo, R. \& Olsen, R.E. (2008) Triacylglycerol-, wax esterand sterol ester-hydrolases in midgut of Atlantic salmon (Salmo salar). Aquaculture Nutrition, 14, 93-98.

Bogevik, A.S., Tocher, D.R., Langmyhr, E., Waagbo, R. \& Olsen, R.E. (In press) Atlantic salmon (Salmo salar) postsmolts adapt lipid digestion according to elevated dietary wax esters from Calanus finmarchicus. Aquaculture Nutrition.

Coca, E., Ribas, B., Trigueros, G., Mtnez-Sarmiento, J., Borque, M., Ortega, D., Sobrino, A., Mallen, A., Depablos, I. \& Fdez-Represa, J.A. (1994) A method for quick determination of bile-acids in bile of patients with biliary lithiasis. Journal of Liquid Chromatography, 17, 1349-1363.

Farquhar, J.W. (1962) Human erythrocyte phosphoglycerides. 1. Quantification of plasmalogens, fatty acids and fatty aldehydes. Biochimica et Biophysica Acta, 60, 80-\&. 
Folch, J., Lees, M. \& Sloane-Stanley, G.H. (1957) A simple method for the isolation and purification of total lipids from animal tissues. Journal of Biological Chemistry, 226, $497-$ 509.

Folmar, L.C. \& Dickhoff, W.W. (1980) The parr-smolt transformation (smoltification) and seawater adaptation in salmonids - a review of selected literature. Aquaculture, 21, 1-37.

Fonseca-Madrigal, J., Bell, J.G. \& Tocher, D.R. (2006) Nutritional and environmental regulation of the synthesis of highly unsaturated fatty acids and of fatty-acid oxidation in Atlantic salmon (Salmo salar L.) enterocytes and hepatocytes. Fish Physiology and Biochemistry, 32, 317-328.

Henderson, R.J. \& Tocher, D.R. (1987) The lipid composition and biochemistry of freshwater fish. Progress in Lipid Research, 26, 281-347.

Hofmann, A.F. (1976) Fat digestion: the interaction of lipid digestion products with micellar bile acid solutions. In: Lipid Absorption: Biochemical and Clinical Aspects (Rommel, K. \& Goebell, H. eds.), pp. 3-18. MTP Press Ltd, UK.

Iwama, G.K. \& Tautz, A.F. (1981) A simple growth-model for salmonids in hatcheries. Canadian Journal of Fisheries and Aquatic Sciences, 38, 649-656.

Krogdahl, A., Sundby, A. \& Olli, J.J. (2004) Atlantic salmon (Salmo salar) and rainbow trout (Oncorhynchus mykiss) digest and metabolize nutrients differently. Effects of water salinity and dietary starch level. Aquaculture, 229, 335-360.

Levings, C.D., Hvidsten, N.A. \& Johnsen, B.O. (1994) Feeding of Atlantic Salmon (Salmo salar L) Postsmolts in a fjord in Central Norway. Canadian Journal of Zoology, 72, 834839.

Lie, O. \& Lambertsen, G. (1985) Digestive lipolytic enzymes in cod (Gadus morhua) - fatty acid specificity. Comparative Biochemistry and Physiology, 80B, 447-450. 
Olsen, R.E. \& Henderson, R.J. (1989) The rapid analysis of neutral and polar marine lipids using double-development HPTLC and scanning densitometry. Journal of Experimental Marine Biology and Ecology, 129, 189-197.

Olsen, R.E. \& Ringø, E. (1997) Lipid digestibility in fish: a review. Recent Research Developments in Lipids Research, 1, 199-265.

Olsen, R.E., Henderson, R.J., Sountama, J., Hemre, G., Ringø, E., Melle, W. \& Tocher, D.R. (2004) Atlantic salmon, Salmo salar, utilizes wax ester-rich oil from Calanus finmarchicus effectively. Aquaculture, 240, 433-449.

Ottera, H., Garatun-Tjeldsto, O., Julshamn, K. \& Austreng, E. (2003) Feed preferences in juvenile cod estimated by inert lanthanid markers - effects of moisture content in the feed. Aquaculture International, 11, 217-224.

Palmquist, D.L. \& Jenkins, T.C. (2003) Challenges with fats and fatty acid methods. Journal of Animal Science, 81, 3250-3254.

Patton, J.S. \& Benson, A.A. (1975) Comparative study of wax ester digestion in fish. Comparative Biochemistry and Physiology, 52B, 111-116.

Patton, J.S., Nevenzel, J.C. \& Benson, A.A. (1975) Specificity of digestive lipases in hydrolysis of wax esters and triglycerides studied in anchovy and other selected fish. Lipids, 10, 575-583.

Place, A.R. (1992) Comparative aspects of lipid digestion and absorption - physiological correlates of wax ester digestion. American Journal of Physiology, 263, R464-R471.

Rikardsen, A.H., Haugland, M., Bjorn, P.A., Finstad, B., Knudsen, R., Dempson, J.B., Holst, J.C., Hvidsten, N.A. \& Holm, M. (2004) Geographical differences in marine feeding of Atlantic salmon post-smolts in Norwegian fjords. Journal of Fish Biology, 64, 1655-1679.

Ringø, E. (1991) Hatchery-reared landlocked Arctic charr, Salvelinus alpinus (L), from lake Takvatn reared in fresh and sea-water. 2. The effect of salinity on the digestibility of 
protein, lipid and individual fatty acids in a capelin roe diet and commercial feed. Aquaculture, 93, 135-142.

Sargent, J.R., McIntosh, R., Bauermeister, A. \& Blaxter, J.H.S. (1979) Assimilation of the wax esters of marine zooplankton by herring (Clupea harengus) and rainbow trout (Salmo gairdnerii). Marine Biology, 51, 203-207.

Sargent, J.R. \& Henderson, R.J. (1986) Lipids. In: The Biological Chemistry of Marine Copepods (Corner, E.D.S. \& O'Hara, S.C.M. eds.), pp. 59-164. Clarendon Press, Oxford.

Sargent, J.R. \& Falk-Petersen, S. (1988) The lipid biochemistry of calanoid copepods. Hydrobiologia, 167, 101-114.

Sheridan, M.A., Woo, N.Y.S. \& Bern, H.A. (1985) Changes in the rates of glycogenesis, glycogenolysis, lipogenesis, and lipolysis in selected tissues of the coho salmon (Oncorhynchus kisutch) associated with parr-smolt transformation. Journal of Experimental Zoology, 236, 35-44.

Sheridan, M.A. (1989) Alterations in lipid metabolism accompanying smoltification and seawater adaptation of salmonid fish. Aquaculture, 82, 191-203.

Stubhaug, I., Lie, O. \& Torstensen, B.E. (2007) Fatty acid productive value and betaoxidation capacity in Atlantic salmon (Salmo salar L.) fed on different lipid sources along the whole growth period. Aquaculture Nutrition, 13, 145-155.

Tocher, D.R. \& Sargent, J.R. (1984) Studies on triacylglycerol, wax ester and sterol ester hydrolases in intestinal ceca of rainbow trout (Salmo gairdneri) fed diets rich in triacylglycerols and wax esters. Comparative Biochemistry and Physiology, 77B, 561-571.

Tocher, D.R. \& Harvie, D.G. (1988) Fatty acid compositions of the major phosphoglycerides from fish neural tissues - (n-3) and (n-6) polyunsaturated fatty acids in rainbow trout (Salmo gairdneri) and cod (Gadus morhua) brains and retinas. Fish Physiology and Biochemistry, 5, 229-239. 
572 Tuchweber, B., Yousef, I.M., Ferland, G. \& Perea, A. (1996) Nutrition and bile formation. $573 \quad$ Nutrition Research, 16, 1041-1080.

574 Usher, M.L., Talbot, C. \& Eddy, F.B. (1991) Effects of transfer to seawater on growth and 575 feeding in Atlantic salmon smolts (Salmo salar L). Aquaculture, 94, 309-326.

576 Wedemeyer, G.A., Saunders, R.L. \& Clarke, W.C. (1980) Environmental factors affecting 577 smoltification and early marine survival of anadromous salmonids. Marine Fisheries $578 \quad$ Review, 42, 1-14.

579

580

581

582

583

584

585

586

587

588

589

590

591

592

593

594

595

596

597 
599

600 Figure 1. Growth performance and feed conversion data of Atlantic salmon freshwater pre601 smolts (FW) or seawater post-smolts (SW) fed dietary fish oil (FO) or Calanus oil (CO) over 60298 days. (a) Weight development, (b) length development, (c) condition factor (k), (d) 603 specific growth rate (SGR), (e) thermal growth coefficient (TGR), (f) feed conversion ratio 604 (FCR). Means \pm SD ( $n=3)$. Values are significantly different $(P<0.05)$ with respect to diet $(*)$ 605 and salinity $(\dagger)$ as determined by multivariate analysis.

606

607

Figure 2. Bile volume (a), osmolality

(b), taurocholate concentration (c), and 608 taurochenodeoxycholate concentration of Atlantic salmon freshwater pre-smolts (FW) and 609 seawater post-smolts (SW) fed dietary fish oil (FO) or Calanus oil (CO) for 98 days. Means 610 \pm SD $(n=3)$. Values are significantly different $(P<0.05)$ with respect to $\operatorname{diet}(*)$ and salinity $(\dagger)$ as determined by multivariate analysis.

612

613

614

615

616

617

618

619

620

621

622 


\section{Tables}

Table 1. Formulation and proximate composition $\left(\mathrm{g} \mathrm{kg}^{-1} \mathrm{diet}\right)$ of diets used in the experiment.

\begin{tabular}{|c|c|c|}
\hline & Fish oil diet & Calanus oil diet \\
\hline Fish meal 24/05+6/05 (1:1) & 596.0 & 596.0 \\
\hline Fish oil & 230.0 & 0.0 \\
\hline Calanus oil & 0.0 & 230.0 \\
\hline Wheat 153/05 & 160.0 & 160.0 \\
\hline Vitamin mixture $^{a}$ & 10.0 & 10.0 \\
\hline Mineral mixture ${ }^{b}$ & 4.0 & 4.0 \\
\hline Carophyll pink (8\%) & 0.3 & 0.3 \\
\hline Yttrium oxide $\left(\mathrm{Y}_{2} \mathrm{O}_{3}\right)$ & 0.1 & 0.1 \\
\hline Protein & 481.0 & 492.0 \\
\hline Lipid & 270.0 & 269.0 \\
\hline Dry matter & 937.0 & 932.0 \\
\hline
\end{tabular}

${ }^{a}$ Diets supplied with following vitamins per kg diet: vitamin D3, 3000 I.E; vitamin E (Rovimix, 50\%), $160 \mathrm{mg}$; thiamine, $20 \mathrm{mg}$; riboflavin, $30 \mathrm{mg}$; pyridoxine- $\mathrm{HCl}, 25 \mathrm{mg}$; vitamin C (Riboflavin Stay C 35\%), $200 \mathrm{mg}$; calcium pantothenate, $60 \mathrm{mg}$; biotin, 1 $\mathrm{mg}$; folic acid, $10 \mathrm{mg}$; niacin, $200 \mathrm{mg}$; vitamin B12, $0.05 \mathrm{mg}$; menadione bisulphite, $20 \mathrm{mg}$.

Diets supplied with following minerals per $\mathrm{kg}$ diet: magnesium, $500 \mathrm{mg}$; potassium, $400 \mathrm{mg}$; zinc, $80 \mathrm{mg}$; iron, $50 \mathrm{mg}$; manganese, $10 \mathrm{mg}$; copper, $5 \mathrm{mg}$.

Table 2. Lipid class composition (\% of total lipid) of dietary and faecal lipids.

\begin{tabular}{|c|c|c|c|c|c|c|}
\hline & \multicolumn{2}{|c|}{$\begin{array}{l}\text { Composition of dietary } \\
\text { lipid (wt.\%) }\end{array}$} & \multicolumn{2}{|c|}{$\begin{array}{l}\text { Composition of freshwater } \\
\text { pre-smolt faeces (wt.\%) }\end{array}$} & \multicolumn{2}{|c|}{$\begin{array}{l}\text { Composition of seawater } \\
\text { post-smolt faeces (wt.\%) }\end{array}$} \\
\hline & Fish oil & Calanus oil & Fish oil & Calanus oil & Fish oil & Calanus oil \\
\hline LPC & 0.9 & 0.7 & $1.8 \pm 0.3$ & $0.6 \pm 0.1$ & $0.7 \pm 0.3$ & $0.7 \pm 0.1$ \\
\hline SM & 0.7 & 0.4 & - & & - & \\
\hline PC & 3.6 & 3.0 & $1.3 \pm 0.1$ & $0.4 \pm 0.1$ & $2.2 \pm 0.3$ & $0.3 \pm 0.5$ \\
\hline PS & 0.6 & 0.4 & - & - & - & - \\
\hline $\mathrm{PI}$ & 1.1 & 0.8 & - & - & - & - \\
\hline PE & 1.3 & 1.2 & $5.4 \pm 1.3$ & $4.1 \pm 0.4$ & $1.6 \pm 1.8$ & $2.6 \pm 0.8$ \\
\hline UPL & 1.0 & 0.3 & $5.7 \pm 0.3$ & $1.2 \pm 0.2$ & $2.2 \pm 0.3$ & $0.5 \pm 0.5$ \\
\hline $\mathrm{C}^{\mathrm{a}}$ & 11.3 & 6.5 & $23.1 \pm 0.4$ & $8.3 \pm 0.6$ & $13.9 \pm 1.8$ & $5.5 \pm 0.6$ \\
\hline FFAlc & & & - & $37.5 \pm 1.6$ & - & $31.8 \pm 1.7$ \\
\hline FFA & 17.2 & 13.0 & $46.7 \pm 4.4$ & $21.3 \pm 2.5$ & $64.4 \pm 1.8$ & $24.8 \pm 2.0$ \\
\hline UNL & - & - & $4.8 \pm 0.4$ & $0.7 \pm 0.3$ & $1.8 \pm 0.4$ & - \\
\hline TAG & 58.2 & 26.0 & $3.9 \pm 0.6$ & $0.5 \pm 0.7$ & $5.9 \pm 1.6$ & $0.9 \pm 0.8$ \\
\hline WE/SE & 4.2 & 47.7 & $7.2 \pm 2.8$ & $25.4 \pm 3.1$ & $7.2 \pm 0.6$ & $32.9 \pm 2.4$ \\
\hline Lipid (\% d.w.) & 27.0 & 26.9 & $4.5 \pm 1.7$ & $11.9 \pm 2.4$ & $6.8 \pm 0.6$ & $14.6 \pm 2.0$ \\
\hline
\end{tabular}

Abbreviations: LPC, lysophosphatidylcholine; SM, sphingomyelin; PC, phosphatidylcholine; PS, phosphatidylserine; PI, phosphatidylinositol; PE, phosphatidylethanolamine; UPL, unidentified polar lipids; C, cholesterol; FFAlc, free fatty alcohols; FFA, free fatty acids; UNL, unidentified neutral lipid; TAG, triacylglycerol; WE/SE, wax ester/sterol ester.

${ }^{a}$ May contain some diacylglycerol. 